\title{
Impacts of climate demonstration on seasonal rainfall patterns in the upper watershed of Senegal
}

\begin{abstract}
Summary
Climate variability, particularly rainfall in West Africa in general and in SahelSaharan region in particular has enormous consequences for the socio-economic development. However, rainy variables, temperatures, relative humilities and flow rates are generally given to study in the context of climate variability. This study aims to determine the influence of climate demonstration on seasonal rainfall patterns in the upper watershed of the river Senegal. To achieve this goal, we adopted a methodology based on the standardized precipitation index. This index allows us to appreciate the level of drought in the upper basin. This is firstly to characterize the climate event from the analysis of the air temperature, the relative humidity of air and the variation of rainfall indices. On the other hand, it comes to comparing the normal monthly rainfall over the period 1955-2014 in order to identify the behavior of seasonal rainfall patterns in the context of climate variability. Therefore, the air temperature and relative humidity are key factors in the temporal variability of seasonal rainfall patterns in the upper watershed of the river Senegal.
\end{abstract}

Keywords: top watershed, climate variability, standardized precipitation index, rainfall patterns, hydrology
Volume 2 Issue 6 - 2018

\author{
Abdoulaye Faty \\ Department of Geography, Faculty of Letters and Human \\ Sciences, University Cheikh Anta DIOP of Dakar, Senegal
}

Correspondence: Abdoulaye Faty, Department of Geography, Faculty of Letters and Human Sciences, University Cheikh Anta DIOP of Dakar, BP 5005 Dakar, Senegal,Tel 00221-77-228-67-83, Email abdowlaye.faty@ucad.edu.sn

Received: November 07, 2018 | Published: December II, 2018

\section{Introduction}

Since the water cycle is one of the major components of climate, the implications of these changes for rainfall patterns are important. Rainfall is the most important factor in climate for both people and ecosystems and is easy to measure. All these reasons make most studies and analyzes look at precipitation much more than at other climate parameters. Characterizing the impact of climate variability on seasonal rainfall patterns is essential for the socio-economic development of the Senegal River watershed. "According to Ardoin$\operatorname{Bardin}^{1} \&$ Bodian et al., ${ }^{2}$ the variability of climatic conditions in West and Central Africa in general and in the upper Senegal River Basin in particular, is no longer to demonstrate. "In the Senegal River Basin, climate variability is explained by an irregular precipitation and high average temperature (about $42^{\circ} \mathrm{C}$ ). "Recent studies ${ }^{3}$ show that climate variability is a phenomenon that has long been studied and characterized. The most important question for both West Africa and other regions of the world is the search for explanatory factors. In this study, we will study annual rainfall data, temperature, relative humidity, and flow data. Correlation of meteorological and hydrological data will reveal the drivers of change. Indeed, the watershed, stretched in latitude, is a transition zone between several climates. The study area is the high watershed of the Senegal River (Figure 1), between longitudes $12^{\circ} 30^{\prime}$ and $9^{\circ} 30^{\prime}$ West and latitudes $10^{\circ} 30$ and $12^{\circ} 30^{\prime}$ North. The high watershed of the Senegal River occupies an area of $218000 \mathrm{~km}^{2}$. With an elongated geographical configuration, the watershed is representative of the sub-Guinean, Sudanese and Sahelian climate. The Sahelian regime (desert climate) is characterized by two seasons, a rainy season from July to September ( 3 months) and a dry season from October to June (9months) which is accentuated by the Harmattan. The humid tropical regime (Sudanese climate) is located in the Guinean part of the basin. This climate is close to the subequatorial climate, characterized by an abundance of rainfall varying, on average (1955-2014), between $1400 \mathrm{~mm}$ and
$2000 \mathrm{~mm}$ per year. This work led to the adoption of a work plan that is elaborated through a description of the methodology, presenting the results and the discussion. A conclusion will complete the work.

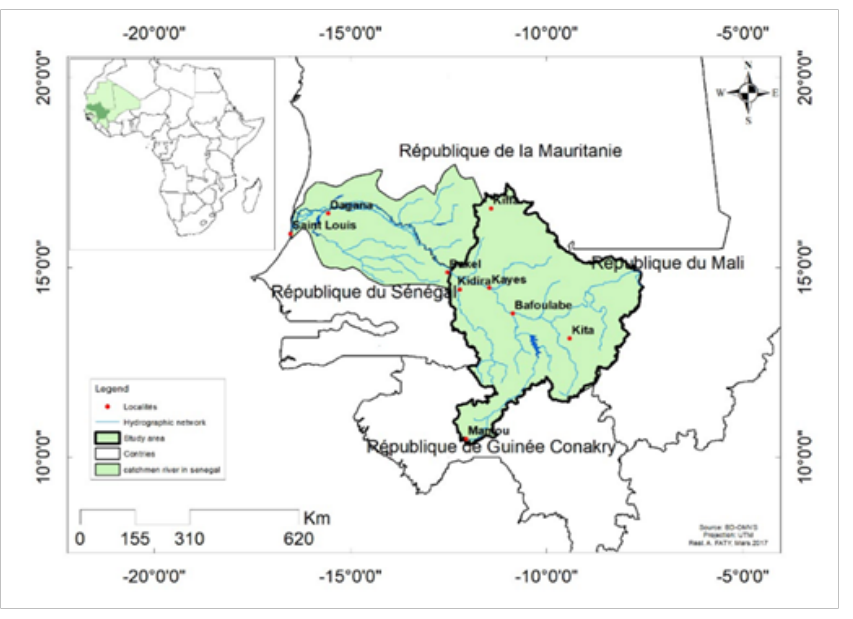

Figure I Presentation upper Senegal river watershed.

\section{Data and methods}

\section{Data}

The data used must respect two important criteria: first, the length of the time series (60 years), and secondly, the quality of the data (the least possible missing or incomplete data). Thus, twenty-two rain stations were selected and four (04) weather stations (temperature and relative humidity data). They present time series over more than 50 years (from 1955 to 2014) and provide good coverage of the study area (Figure 2). This study focuses on the upper Senegal River Basin. The data were homogenized by the Brunet-Moret ${ }^{4}$ regional 
vector method (1978). The Regional Vector is above all a method of data criticism (and incidentally reconstruction of missing data), developed at the former ORSTOM - IRD in the seventies, with the aim of homogenizing rain data. Regarding flow data, we chose eight hydrometric stations: Dibia, Sokotoro and Oualia on the Bakoye; Bafing-Makana and Dakka Saidou on the Bafing; Kidira on the Faleme; Bakel on Senegal. The time series of the flow data is from 1955 to 2014. The Manantali dam influences the flows on the Bafing and Senegal. The regional vector method made it possible to obtain flow data of very good quality. All the data has been provided by the Organization for the Development of the Senegal River (OMVS). However, a hydro-rainfall map is produced for better spatial location of stations in the Senegal River basin (Figure 2).

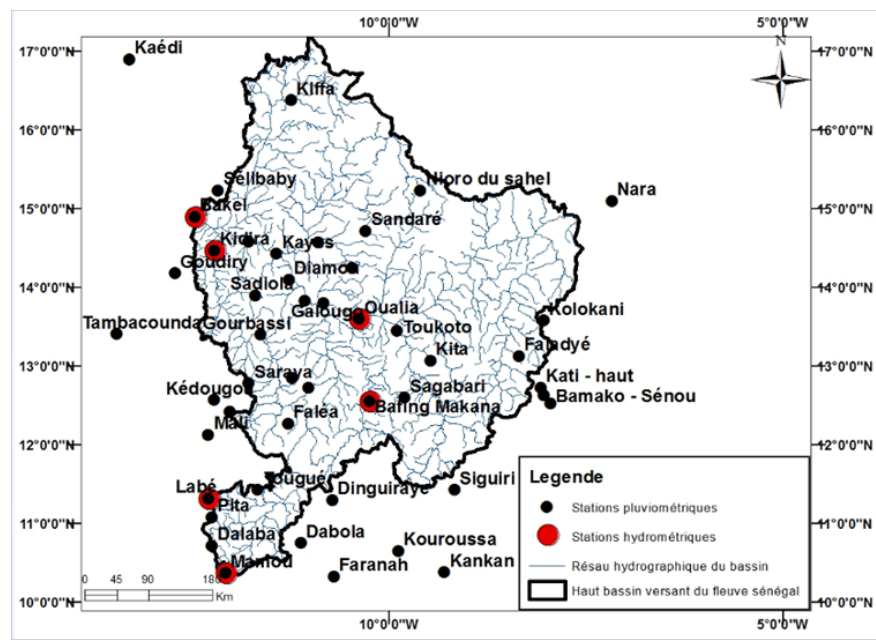

Figure 2 Map of hydro-basin rainfall stations.

\section{Methods}

In this paper, we have adopted the Standardized Precipitation Index (SPI) approach. The Standardized Precipitation Index is a tool that has been developed for the definition and monitoring of drought. It is based on the appreciation of the level or frequency of drought in the upper Senegal River Basin.

\section{Rainfall data processing}

Over the period 1955-2014, the average rainfall at the twenty-two pluviometric stations is $1108.16 \mathrm{~mm} /$ year. The spatial distribution of rainfall is very uneven: the Selibabi station, located to the north of the study area, recorded an average of $549.8 \mathrm{~mm}$, compared to $1824.5 \mathrm{~mm}$ in Mamou, in the southern part (Table 1).

\section{Standardized precipitation index}

The Standardized Precipitation Index or Standardized Precipitation Index has the following formula:

$$
S P I=(X i-X m) / S i
$$

Where $\mathrm{Xi}$ is the cumulative rainfall for a year $\mathrm{i}$;

$\mathrm{Xm}$ and $\mathrm{Si}$ are respectively the mean and the standard deviation of the series of annual rainfall observed.

According to the work of Bergaoui et al..$^{5}$ Ardoin-Bardin ${ }^{1}$ the rainfall index gives the level of severity of drought over a series of annual rainfall (Table 2). Negative values indicate dry periods and positive values mark wet seasons.

Table I Average of |955-20I4 rains stations

\begin{tabular}{ll}
\hline Stations & Average annual rains \\
\hline Selibaby & 549,8 \\
kidira & 583,1 \\
kayes & 651,6 \\
koniakary & 688 \\
Diamou & 694,4 \\
Bafoulabé & 769,2 \\
Tambacounda & 807,3 \\
BafingMakan & 818,1 \\
Oualia & 865,4 \\
Gourbassi & 872,1 \\
Bakel & 972,8 \\
Saraya & 1045,7 \\
Sagabari & 1086,7 \\
Kenieba & 1193,8 \\
Kedougou & 1202,4 \\
Dinguiraye & 1394,5 \\
Dabola & 1495,4 \\
Faranah & 1545,9 \\
Labé & 1579,5 \\
Mamou & 1824,5 \\
Mali & 1854,1 \\
Dalaba & 1885,4 \\
Msicaton & \\
\hline
\end{tabular}

Table 2 Classification of the drought in relation to the value of the index standardized precipitation (SPI)

\begin{tabular}{ll}
\hline SPI class & Degree of drought \\
\hline $\mathrm{SPI}>2$ & Extreme humidity \\
$1<\mathrm{SPI}<2$ & High humidity \\
$0<\mathrm{SPI}<1$ & Moderate humidity \\
$-1<\mathrm{SPI}<0$ & Moderate drought \\
$-2<\mathrm{SPI}<-1$ & Strong drought \\
$\mathrm{SPI}<-2$ & Extreme drought \\
\hline
\end{tabular}

\section{Results and discussion}

\section{Results}

\section{Meteorological parameters}

\section{Average temperatures}

The temperatures give an overview of the thermal character of each station. The evolution of temperatures is analyzed from the monthly average characteristic values presented in Table 3 . The mean monthly maximum temperature values are between $32.6^{\circ} \mathrm{C}$ and $34.7^{\circ} \mathrm{C}$ and are located in the last part of the dry season, that is to say in March at Bakel 
and Kidira, April at Baffing Makana and Oualia. They are explained by the presence of the harmattan flow, hot and dry; it is during this period that extreme daily temperatures are recorded. Temperatures are minimal in January and December with $23.5^{\circ} \mathrm{C}$ for Baffing Makana and $25^{\circ} \mathrm{C}$ for the station of Oualia, $27.9^{\circ} \mathrm{C}$ for Bakel and $27.8^{\circ} \mathrm{C}$ for Kidira (Figure 3). During this period, the climate becomes mild (ie fresh) with the arrival of cold air masses from the northwest.

\section{Relative humidity}

Relative humidity is the ratio between the weight of the water vapor contained in the air and the one it would contain if it were saturated at the same temperature. ${ }^{1}$ The average relative humidity values are roughly equal to Baffing Makana, Bakel, Kidira and Oualia with a slight increase for Baffing Makana. This is due to the abundance of rainfall at Baffing Makana. The maximum values of average relative humidity were recorded in August at the four stations, Baffing Makana (82.1\%), Bakel (77.4\%), Kidira (80.5) and Oualia (80.9\%). The monthly minimum averages in February are $20.5 \%$ in Baffing Makana, $8.8 \%$ in Bakel, $10 \%$ in Kidira and $17.7 \%$ in Oualia (Table 4). Average relative humidity is still above $50 \%$ during the rainy season. Table 4 \& Figure 4 reflect this situation.

\section{Upper basin precipitation study}

In the study area, the standardized precipitation method indicates a situation predominantly dominated by drought (Table 5 ). The average values of the SPI index are generally positive for the years 1955-64 (0.98), whereas they are negative for all the following decennals: -0.46 on average, with values between -0.28 in $1975-1984$ and -1.05 in 1995-2004 (Table 5). Moreover, the average of the annual data of the 22 pluviometric stations varies between $1102 \mathrm{~mm}$ over the period 1955-64 to $889 \mathrm{~mm}$ for the period 2005-2014, ie a decrease of 313 $\mathrm{mm}$. High or extreme humidity occurs in $49.79 \%$ of cases over the decade 1955-1964 and in 21.28\% of cases over the decade 1965-1974, a decrease of $28.51 \%$ (Table 6 ). While over the same period, moderate conditions are recorded at around $8.72 \%$ and $25.11 \%$ (Table 6 ). These results explain the character of the severity of the climate in the study area. The climate crisis that has hit the Sudano-Sahelian environment has so far been manifested by an increase in moderate to severe droughts, and not by extreme droughts. Moderate drought, outside the first two decades (1955-1974) is largely dominant over most other decades except $1995-2004$, with only $39.15 \%$ of cases of moderate drought, but $51.06 \%$ of drought strong. Figure 5 presents the evolution of the annual average values of the SPI index for four rainfall stations over the period 1955-2014. These stations are distributed more or less homogeneously over the upper Senegal River Basin. In the 1950s and 1960s, except for Bakel, everywhere there were many positive values, often greater than 1. Rainfall then became almost systematically negative until the beginning of the 1990s. This deficit was particularly marked during the 1990s. 1980. Towards the end of the observation period, rainfall remains in deficit, but index values rarely drop below one, while positive values are slightly more frequent. In the dry period, the Bakel station continues to stand out, since the deficit is not systematic. In Figure 5, only a few limited areas, with relative drought. The following decades appear almost everywhere marked by drought, especially in the 1980s. The mapping of the mean values of the index of coefficients of variation over different periods highlights the opposition between the dry years 1955-1964 and the drier years 1970-2014. This joins the results found in the literature Paturel et al. ${ }^{6}$ Servat et al. ${ }^{7}$ Lubes-Niel et al. ${ }^{8}$ Ardoin- Bardin., ${ }^{1}$ In average, in all stations the values increase from 0.05 to 0.44 over the decades of the period $1955-1964$ to values below -0.35 (-036 to -0.49$)$ over the decades of 1970 to 2014. Positive values occupy a very small area at the southern end of the basin (which is related to the climate of the Sudano-Guinean zone and the presence of the Fouta Djalon massif). This area narrowed after 1969.

\section{Annual flow analysis}

In the tropical zone, flows are a direct response to rainfall impulses, the transfer of which can be subject to various modalities depending on the size, configuration, relief, geology and soils of the basin. The increase of the modules is due to the improvement of the rainfall, which however remains very fluctuating from one year to another, so that the tendency to rebuild the resources remains very uncertain and makes it more difficult to forecast the availability. Figure 6 shows a variation in annual average flow data. The Bakel station records $558.8 \mathrm{~m}^{3} / \mathrm{s}$ whereas at the Sokotoro station, the average annual flow represents only.

\section{Synthetic analysis}

A comparable drop in the river's water supply accompanies the drop in rainfall in the basin. The average annual flow of the river is part of a continuous cycle of decline since the beginning of the last century. This explains the character of the river's diet. This diet is unimodal because the only mode of feeding is rain. This rain is irregular and especially remarkable decreases with other parameters such as relative humidity. In addition to the downward trend in longterm flows, the river's hydraulic regime is characterized by high interannual (year-to-year) and annual (month-to-month) variability over the course of the year (same year). The saw tooth evolution of annual average flows is reminiscent of rainfall (see below). Whether in a dry or wet sequence, a year of high water level can be followed by a year of severe deficits. We are in the field of unpredictability. Through these graphs, we can see that from 2002, there is a drastic drop in the relative humidity, the average rainfall and the average flow of the basin. This situation of declining hydrological inputs mainly explains the advent of a new drought cycle.

\section{Discussion}

The IPS method has made it possible to highlight the general downward trend in rainfall from the 1961-70 decade, which worsened in the following decades. However, the entire basin was not affected in the same way given the influence of local climates. This result is consistent with statistical tests applied to annual rainfall. This climatic variability is manifested by a decrease in relative humidity and an increase in air temperatures, which results in an affection of the hydrological cycle in general and the formation of rain clouds, hence the low rainfall heights annual. It appears that the temperature and the relative humidity of the air are factors of the temporal variability of the seasonal rainfall regimes in the high watershed of the Senegal River. In fact, these atmospheric parameters strongly influence the temporal variability of rainfall variables. However, the previous results of the study show a decrease in rainfall variables as well as relative humidity and a rise in temperatures over the last decades in the watershed. On the basis of these observations, it can be said that the variability of seasonal rainfall patterns depends partly on the drop in relative humidity and, on the other hand, on the rise in air temperature. In a perspective of rising air temperature, we are in the process of dreading a change in seasonal climate patterns in the watershed. The results obtained can be related to other works. Based on the results of the 
work of Richard et al., ${ }^{9}$ during the twentieth century, the frequency of ENSO-LNSO events is positively correlated with global temperature and their intensity is highest over the period after 1970. Recent studies by Richard, ${ }^{9}$ at the same time in southern Africa, their effect on rainfall has increased and droughts have become more pronounced and widespread in space. These results can be related to the increase in magnitude of the variations described around 1970 (Table 7).

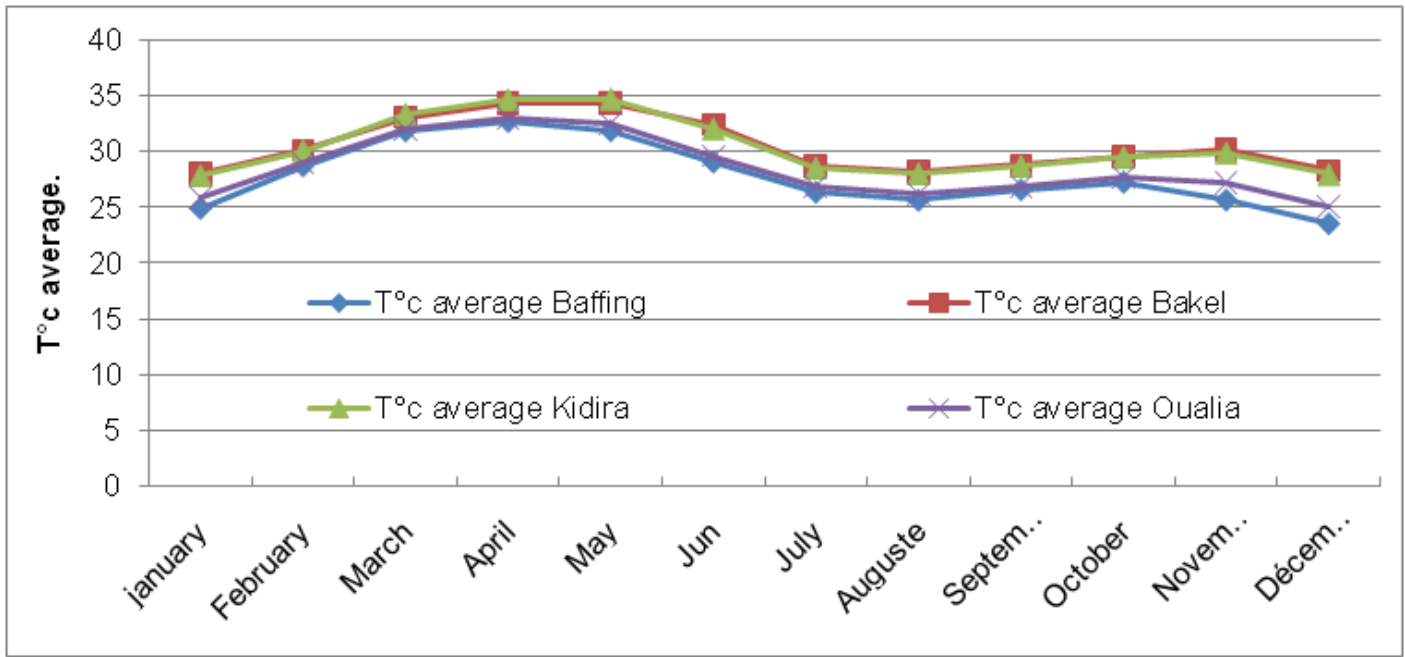

Figure 3 Evolution of the average monthly temperatures.

Table 3 Evolution of the monthly average temperature (1955-2014)

\begin{tabular}{lllll}
\hline Period & $\mathbf{T}^{\circ} \mathbf{C}$ moy baffing & $\mathbf{T}^{\circ} \mathbf{C}$ moy bakel & $\mathbf{T}^{\circ} \mathbf{c}$ moy kidira & $\mathbf{T}^{\circ} \mathbf{c}$ moy oualia \\
\hline January & 24,9 & 27,9 & 27,8 & 25,8 \\
Fébruary & 28,7 & 30,0 & 30,1 & 28,9 \\
March & 31,8 & 33,0 & 33,3 & 32,0 \\
April & 32,6 & 34,2 & 34,6 & 33,0 \\
May & 31,8 & 34,3 & 34,7 & 32,5 \\
Jun & 29,0 & 32,4 & 32,0 & 29,5 \\
July & 26,3 & 28,6 & 28,5 & 26,8 \\
Auguste & 25,6 & 28,1 & 28,0 & 26,1 \\
September & 26,5 & 28,7 & 28,6 & 26,9 \\
October & 27,2 & 29,4 & 29,4 & 27,7 \\
November & 25,6 & 30,1 & 29,8 & 27,1 \\
December & 23,5 & 28,2 & 27,9 & 25,0 \\
\hline
\end{tabular}

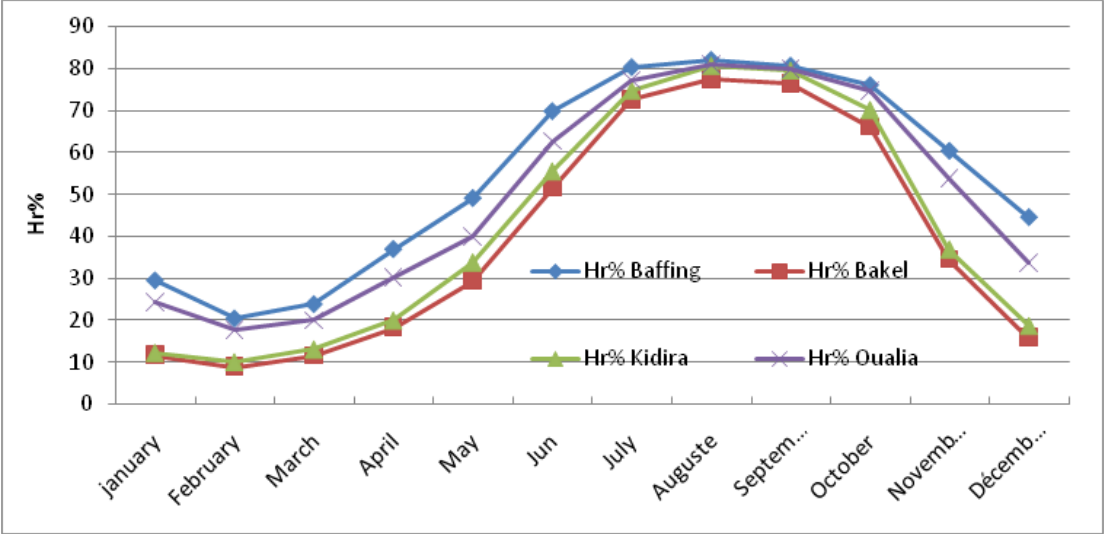

Figure $4 \mathrm{Graph}$ of the monthly average relative humidity. 


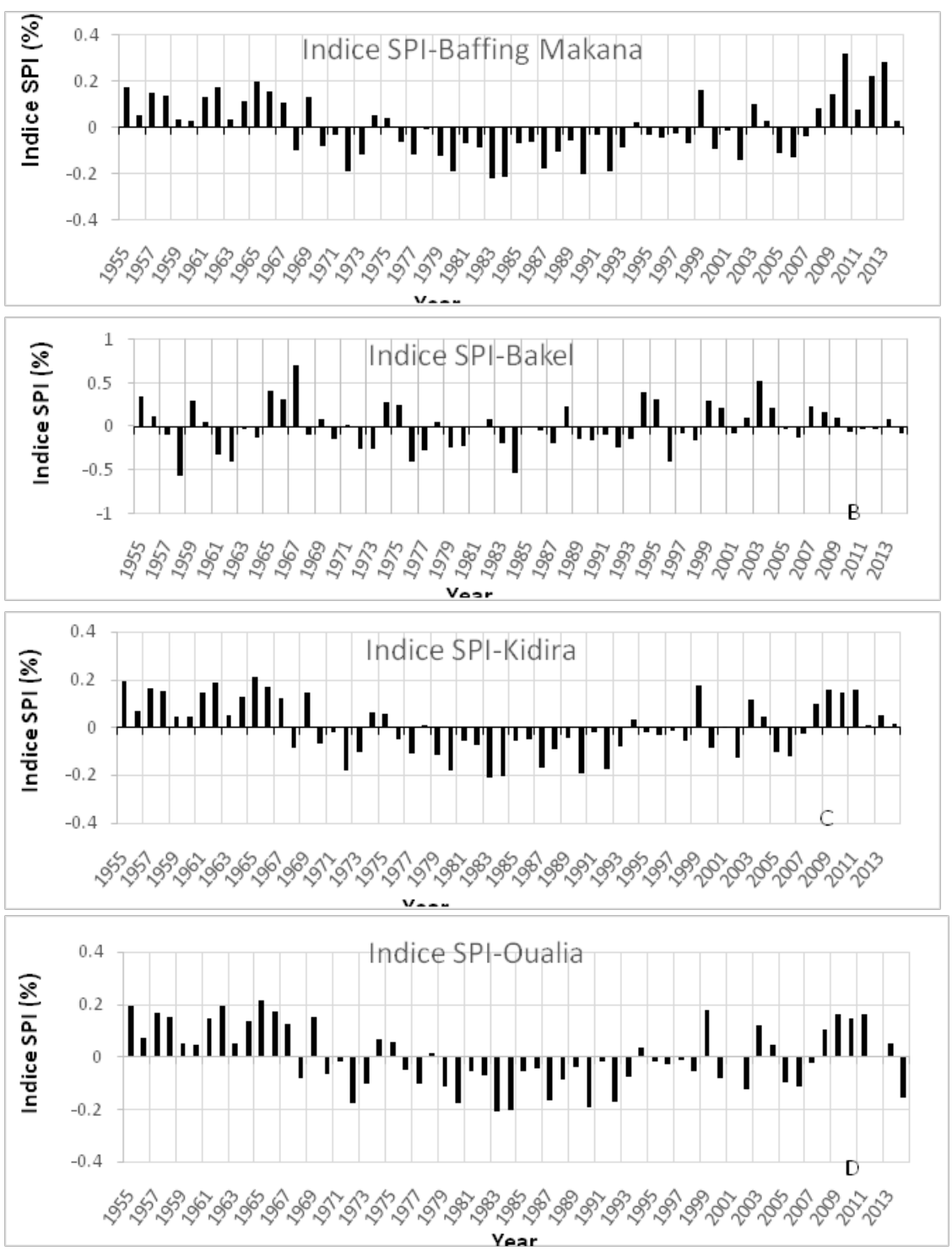

Figure 5(A-D) Annual values of the Standardized Precipitation Index of the four rainfall stations over the period 1955-2014.

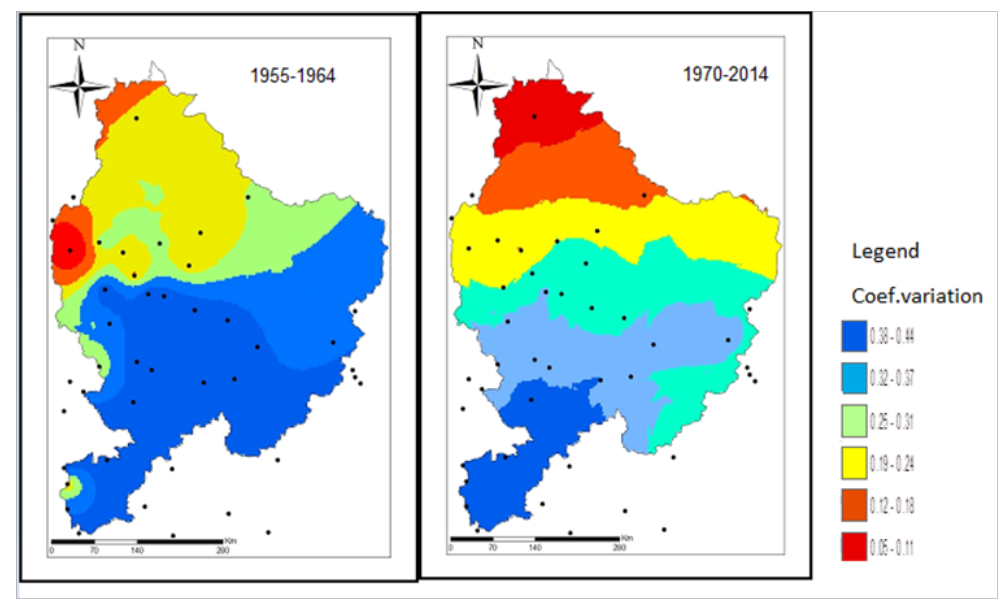

Figure 6 Map of spatial variation of the standardized indices 1955 to 2014 rains. 
Table 4 Evolution of relative humidity (\%) monthly average of 1955-20I4

\begin{tabular}{lllll}
\hline Period & Hr\% baffing & Hr\% bakel & Hr\% kidira & Hr\% oualia \\
\hline january & 29,6 & 11,7 & 12,2 & 24,2 \\
February & 20,5 & 8,8 & 10,0 & 17,7 \\
March & 23,9 & 11,5 & 13,0 & 20,0 \\
April & 37,0 & 18,3 & 19,9 & 30,3 \\
May & 49,2 & 29,4 & 33,7 & 39,9 \\
Jun & 69,9 & 51,5 & 55,4 & 62,6 \\
July & 80,4 & 72,4 & 74,7 & 77,2 \\
Augute & 82,1 & 77,4 & 80,5 & 80,9 \\
September & 80,7 & 76,4 & 79,4 & 79,9 \\
October & 76,1 & 66,1 & 70,0 & 74,7 \\
November & 60,5 & 34,4 & 36,8 & 53,9 \\
December & 44,7 & 15,9 & 18,6 & 33,7 \\
\hline
\end{tabular}

Table 5 Average annual values of the standardized precipitation index (SPI) for the period I955-20I4

\begin{tabular}{lllllll}
\hline \multirow{2}{*}{ descriptors } & \multicolumn{2}{l}{ Wet periods } & \multicolumn{2}{l}{ Dry periods } \\
\cline { 2 - 7 } & $\mathbf{I 9 5 5 - 6 4}$ & $\mathbf{I 9 6 5 - 7 4}$ & $\mathbf{I 9 7 5 - 8 4}$ & $\mathbf{1 9 8 5 - 9 4}$ & $\mathbf{1 9 9 5 - 0 4}$ & $\mathbf{2 0 0 5 - 1 4}$ \\
\hline Average & 0.98 & -0.49 & $-0,28$ & -0.49 & -1.05 & -0.65 \\
Maximum & $\mathrm{I} .4$ & 0.96 & 0.5 & -0.58 & -0.35 & 1.08 \\
Minimum & 0.3 & -0.47 & -0.9 & -1.58 & -1.38 & -0.52 \\
Standard deviation & 0.35 & 0.42 & 0.56 & 0.43 & 0.4 & 0.66 \\
Medium difference & 0.29 & 0.3 & 0.37 & 0.34 & 0.24 & \\
\hline
\end{tabular}

Table 6 Frequencies (\% of stations / years) classes Standardized Precipitation Index (SPI) for the period I955-20I4

\begin{tabular}{llllllll}
\hline \multirow{2}{*}{ Descriptor } & Wet period & \multicolumn{2}{l}{ Dry period } & & & \\
\cline { 2 - 7 } & $\mathbf{1 9 5 5 - 6 4}$ & $\mathbf{I 9 6 5 - 7 4}$ & $\mathbf{I 9 7 5 - 8 4}$ & $\mathbf{1 9 8 5 - 9 4}$ & $\mathbf{I 9 9 5 - 0 4}$ & $\mathbf{2 0 0 5 - 1 4}$ \\
\hline Extreme humidity & 8,09 & 5,32 & 0,43 & 0,42 & 0 & 0,43 & 2,86 \\
High humidity & 41,70 & 15,96 & 4,26 & 3,40 & 0 & 3,40 & 13,62 \\
Moderate humidity & 40,64 & 53,62 & 25,96 & 35,75 & 5,53 & 10,64 & 29,98 \\
Moderate drought & 8,72 & 20,85 & 52,34 & 51,06 & 39,15 & 58,72 & 38,80 \\
Strong drought & 0,85 & 4,26 & 16,60 & 9,36 & 51,49 & 23,83 & 13,89 \\
Extreme drought & 0 & 0 & 0,43 & 0 & 3,83 & 2,98 & 0,85 \\
Total & 100 & 100 & 100 & 100 & 100 & 100 & 100 \\
\hline
\end{tabular}

Table 7 Statistical data of the annual flow of the Senegal river basin top

\begin{tabular}{lll}
\hline Coefficient of variation & Avg. obs. & Avg. calculated \\
\hline 0,314 & 239 & 251,6 \\
0,459 & 564,3 & 601,8 \\
0,385 & 188,4 & 195,6 \\
0,613 & 117,6 & 112,9 \\
\hline
\end{tabular}

\section{Conclusion}

The treatments carried out show a persistent reduction of rains over the 1970s, 1980s and 1990s compared to previous years (19551964). In the high Senegal basin, according to the SPI, the drought generally keeps a moderate character and is very rarely extreme. Thus, this work made it possible to have an idea about the potential impacts of climate change on rainfall trends in the upper Senegal River Basin. The analysis of hydrometeorological data shows a decrease in flows and precipitation. This decline is visible through the appearance of the drought cycle. The hydrological drought has caused enormous 
disturbances in terms of water control, agriculture, the degradation of wildlife reserves and especially to contribute significantly to food insecurity in the upper Senegal River Basin.

\section{Acknowledgment}

The author thanks Professor PIERRE HUBERT for helping him during difficult times.

\section{Conflicts of interest}

The author declares that there are no conflicts of interest.

\section{References}

1. Ardoin-Bardin S. Hydro-climatic variability and impacts on water resources of major watersheds in the Sudano-Sahelian zone. Thesis of Montpellier University. 2004;II:440.

2. Bodian A, Dacosta H, Dezetter A. Spatiotemporal characterization of the rainfall regime of the upper Senegal River Basin in a context of climatic variability. Physio-Geo Physical Geography and Environment. 2011;5:116-133.

3. Kouassi M, Soro TD, Soro N, et al. Climate variability and its impact on water resources in the square degree of Grand-Lahou (south-west of Côte d'Ivoire). Physio-Geo - Physical Geography and Environment. 2011;5:55-73.

4. Brunet-Moret. Search for a fit test. ORSTOM notebook, hydrology series. 1978;XV(3):261-280.

5. Bergaoui M, Alouini A. Characterization of meteorological and hydrological drought: the case of the Mercide Siliana watershed in Tunisia. Drought. 2001;12(4):205-213.

6. Paturel JE, Servat É, Kouamé B, et al. Procedures for identifying "breaks" in time series; change in rainfall patterns in non-Sahelian West Africa. In: Tropical hydrology. 1996;238:1-12.

7. Servat É, Paturel JE, Lubes-Niel H, et al. Different aspects of the variability of rainfall in West and Central Africa non-Sahelian. Journal of Water Sciences. 1999;12(2):363-387.

8. Lubes-Niel H, Servat E, Paturel JE, et al. Different aspects of the variability of rainfall in West and Central Africa. Review of Water Sciences. 1999;12(2):363-387.

9. Richard Y, Camberlin P, Fauchereau N. El Nino-la Nina: intraseasonal consistency of interannual rainfall variability in South Africa. Geographical Space. 2002;(1):63-72. 